OPEN ACCESS

Edited by:

Åke Sjöholm,

Gävle Hospital, Sweden

Reviewed by:

Riccardo Sarzani,

Marche Polytechnic University, Italy

Michel Burnier,

CHU de Lausanne

(CHUV), Switzerland

*Correspondence:

Samuel N. Heyman

heyman@cc.huji.ac.il

Zaid Abassi

abassi@tx.technion.ac.il

Specialty section: This article was submitted to

Clinical Diabetes,

a section of the journal

Frontiers in Endocrinology

Received: 02 December 2019

Accepted: 26 March 2020

Published: 07 May 2020

Citation:

Heyman SN, Bursztyn M, Szalat A,

Muszkat M and Abassi Z (2020)

Fasting-Induced Natriuresis and SGLT:

A New Hypothesis for an Old Enigma.

Front. Endocrinol. 11:217.

doi: 10.3389/fendo.2020.00217

\section{Fasting-Induced Natriuresis and SGLT: A New Hypothesis for an Old Enigma}

\author{
Samuel N. Heyman ${ }^{1 *}$, Michael Bursztyn ${ }^{1}$, Auryan Szalat ${ }^{1}$, Mordechai Muszkat ${ }^{1}$ and \\ Zaid Abassi ${ }^{2,3 *}$ \\ ${ }^{1}$ Department of Medicine, Hadassah Hebrew University Hospital, Mt. Scopus, Jerusalem, Israel, ${ }^{2}$ Department of Physiology \\ and Biophysics, Ruth and Bruce Rappaport Faculty of Medicine, Technion-IIT, Haifa, Israel, ${ }^{3}$ Department of Laboratory \\ Medicine, Rambam Health Care Campus, Haifa, Israel
}

For years, physicians and scientists were enthralled by the enigmatic phenomenon of fasting-associated diuresis and natriuresis and their reversal by feeding. This abrupt response is most prominent in obese and hypertensive individuals, and if repeated once and again may lead to the attenuation of blood pressure and improve insulin sensitivity. The mechanisms involved in early natriuresis and diuresis remain speculative as the renin-angiotensin-aldosterone axis and natriuretic peptides are initially suppressed. Based on gained insight using sodium-glucose transporter 2 (SGLT-2) inhibitors, herein, we propose a role for enhanced post-prandial proximal tubular sodium uptake, mediated by increased glucose-sodium co-transport, as daily filtered glucose increases, and reduced sodium uptake when glucose reabsorption diminishes. This phenomenon might be more pronounced in diabetics due to prolonged post-prandial hyperglycemia and intense SGLT-driven transport. Our hypothesis may also provide a physiologic basis for fasting-related reduced blood pressure in hypertension. This theory deserves challenging by experimental and clinical studies.

Keywords: fasting, SGLT-2, hypertension, diabetes, obesity, glucose, sodium, natriuresis

\section{INTRODUCTION}

For five decades, physicians and scientists are enthralled by the enigmatic phenomenon of fasting-associated diuresis and natriuresis and their reversal by the administration of glucose $(1,2)$. These observations were mainly of clinical interest in the context of hospitalized patients for an intensive low caloric diet in the aim of losing weight (3). Interestingly, fasting natriuresis and carbohydrate-induced antidiuresis were noted to be especially prominent among hypertensive patients (4), and in spontaneously hypertensive rats (5), and develop quickly with natriuresis following an overnight fasting, with its abrupt reversal following glucose administration. Anecdotal layman reports of a desired 1-kg weight loss following fasting for a day (also reversed upon refeeding) likely reflect this phenomenon. Specific measurements in a fasting hospitalized patient could correlate exactly the amount of peak daily natriuresis $(68 \mathrm{mEq})$ and diuresis/negative fluid balance $(0.9 \mathrm{~L})$ with loss of weight $(0.9 \mathrm{~kg})$, and the immediate reversal with carbohydrate intake (3).

Various mechanisms have been proposed to explain fasting natriuresis and diuresis and their reversal. As discussed below, insulin and the activation of the renin-angiotensin-aldosterone (RAAS) system have been suggested to enhance post-feeding sodium retention, while glucagon, 
natriuretic peptides, ketones, and the sympathetic system have been evaluated as mediators of fasting natriuresis. Yet, their role in these processes has not been conclusively established.

While no decisive explanation has been offered up to now, a new potential player in the involved mechanisms came to mind in light of the recent clinical trials and outstanding results related to the use of novel anti-diabetic oral medications of the sodium-glucose co-transporter 2 inhibitor (SGLT2-I) family.

SGLT2 inhibition is associated with enhanced natriuresis and diuresis, the consequence of diminished glucose-sodium co-transport in proximal tubules. These physiologic responses likely participate in the profound and very early reduction in cardiovascular morbidity and mortality in high-risk patients treated with SGLT2-I, in attenuating congestive heart failure and in the better control of hypertension (6). In the perspective of these outcomes with SGLT2-I, it is tempting to assume that alterations in sodium handling in proximal tubules, attributed to changes in filtered glucose via SGLT, might explain fasting diuresis and post-prandial sodium retention.

\section{HYPOTHESIS}

Glucose and sodium co-transport takes place at proximal tubular segments by the SGLT family, including SGLT1 and SGLT2 at the apical membrane and by GLUT 2 at the basolateral membrane. Fasting is associated with stable plasma glucose levels, provided initially by glycogenolysis, and later on by gluconeogenesis. Thus, glucose-sodium co-transport at the proximal tubule remains stable over time during fasting. In contrast, plasma glucose transiently increases following meals, with enhanced filtered glucose, leading to an increase in sodium-glucose co-transport. This is associated with an enhanced cortical oxygen consumption as the inhibition of SGLT improves cortical oxygenation (7). The following two hypothetical examples illustrate the postulated impact of meals on sodium tubular uptake. For the simplicity of the discussion, we ignore possible additional alterations in the glomerular filtration rate (GFR) and in sodium handling along the distal nephron segments.

\section{Example 1}

A non-diabetic patient with stable glucose levels of $70 \mathrm{mg} / \mathrm{dl}$ and a GFR of $100 \mathrm{ml} / \mathrm{min}$ will have a glucose reuptake of $70 \mathrm{mg} / \mathrm{min}$, about $100 \mathrm{~g} / 24 \mathrm{~h}$. This individual, now having three meals per day with three post-prandial increments of glucose levels to $140 \mathrm{mg}$ for an hour (additional $70 \mathrm{mg} / \mathrm{min}$ of filtered glucose for an hour, three times a day), will have an extra $12.6 \mathrm{~g}$ of glucose reabsorption per day (Figures 1A,B).

\section{Example 2}

An obese individual with a poorly controlled type 2 diabetes mellitus (T2DM), fasting glucose levels of $140 \mathrm{mg} / \mathrm{dl}$ without glycosuria, and with a GFR of $100 \mathrm{ml} / \mathrm{min}$ will reabsorb $140 \mathrm{mg}$

Abbreviations: $V$, urine volume; GFR, glomerular filtration rate; $\mathrm{CH}_{2} 0$, free water clearance; T2DM, type 2 diabetes mellitus; ANP, atrial natriuretic peptide; SGLT, sodium-glucose transporter. glucose/min, about $200 \mathrm{~g} / 24 \mathrm{~h}$ while fasting. This patient will have protracted post-prandial hyperglycemia, for example, $210 \mathrm{mg} / \mathrm{dl}$ glucose for $6 \mathrm{~h} /$ day, an additional $70 \mathrm{mg} / \mathrm{min}$ glucose reuptake for $6 \mathrm{~h}$, culminating with an extra $25.2 \mathrm{~g}$ of renal glucose handling per day. Excluding $5 \mathrm{~g}$ of glycosuria leaves us with an additional 20.2 g of daily tubular glucose reuptake as compared to fasting (Figures 1C,D).

As the proximal tubular transport of sodium and glucose is matched with a 1:1 molar ratio for SGLT2, the non-diabetic individual (example 1), moving from a 24-h fast to regular eating, will have an additional daily uptake of $70 \mathrm{mEq}$ sodium, while the diabetic patient (example 2) will have an enhanced sodium reuptake of $111 \mathrm{mEq}$. These figures correspond to an additional retention of 4 and $6.5 \mathrm{~g}$ of sodium chloride per day for the non-diabetic and diabetic individuals, respectively. It translates to added water retentions of 0.5 and $0.66 \mathrm{~L}$, respectively, in order to maintain extracellular osmolality, roughly the anecdotal reported acute weight reduction following fasting for a day, immediately reversed upon eating.

These figures are solely extrapolated from a plausible enhanced sodium transport by SGLT2. They are likely somewhat higher since some $10 \%$ of sodium-glucose co-transport is carried out by SGLT1 with a 2:1 transport molar ratio, respectively (8). Furthermore, an enhanced expression of co-transporters in the diabetic kidney minimizes glycosuria and intensifies sodium retention.

\section{DISCUSSION}

Our proposed hypothesis might explain the enigmatic phenomenon of fasting-induced diuresis and natriuresis in the absence of other reasonable established explanations. Our hypothesis may also shed light on the beneficial impact of fasting on resistant high blood pressure, with fasting for 2 days markedly attenuating hypertension in spontaneously hypertensive rats (5), while intermittent fasting without overall caloric deprivation reduces blood pressure in rats and humans $(9,10)$.

The mechanism(s) of fasting natriuresis have been thoroughly explored, mostly throughout 1970-2000, with no clear-cut explanations for this phenomenon. Noteworthy is that the mediators governing sodium and water handling may change over time, with the activation of physiologic responses to effective volume depletion following protracted fasting and sodium loss. Since fasting natriuresis develops rapidly, late neuroendocrine responses are likely secondary adaptive responses rather than causative factors.

Studying healthy individuals at baseline and following fasting for 5 days, Schloeder et al. (2) found that, after a huge water load (suppressing vasopressin), natriuresis was substantially enhanced in the fasting state as compared to a pre-fast period, an effect blunted within $20 \mathrm{~min}$ following glucose administration. Based on an increase in urine volume $(V) / G F R$ and a decline in $\mathrm{CH}_{2} \mathrm{O} / \mathrm{V}$ post-hydration, they concluded that fasting leads to a reduced sodium uptake by both proximal and distal tubular segments (2). This happens despite a profound increase in aldosterone secretion already at the early fasting phase (11). 


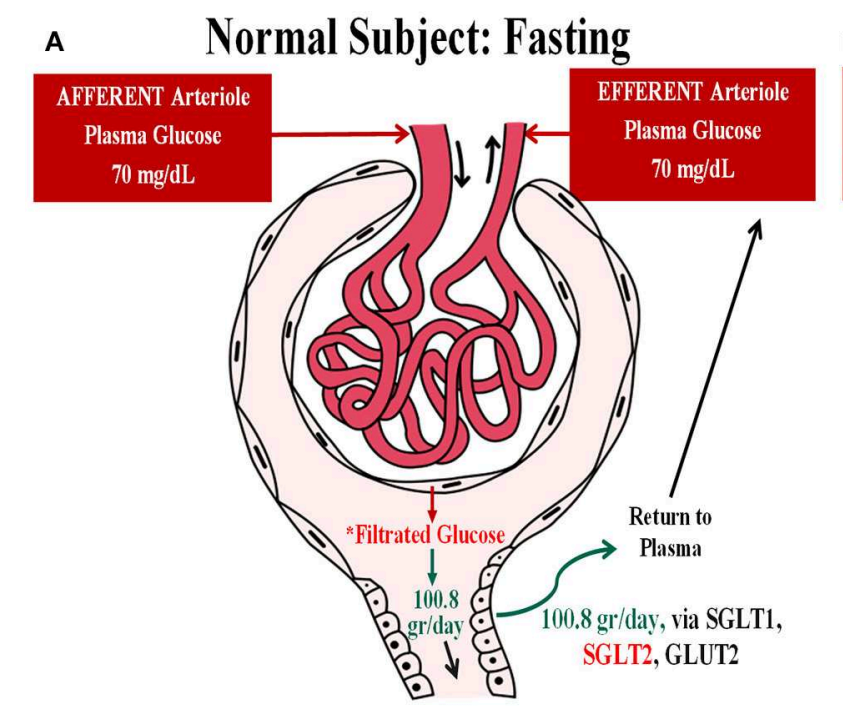

Urinary glucose excretion $=0$ gr $/$ day в Normal Subject: Postprandial (3 meals)

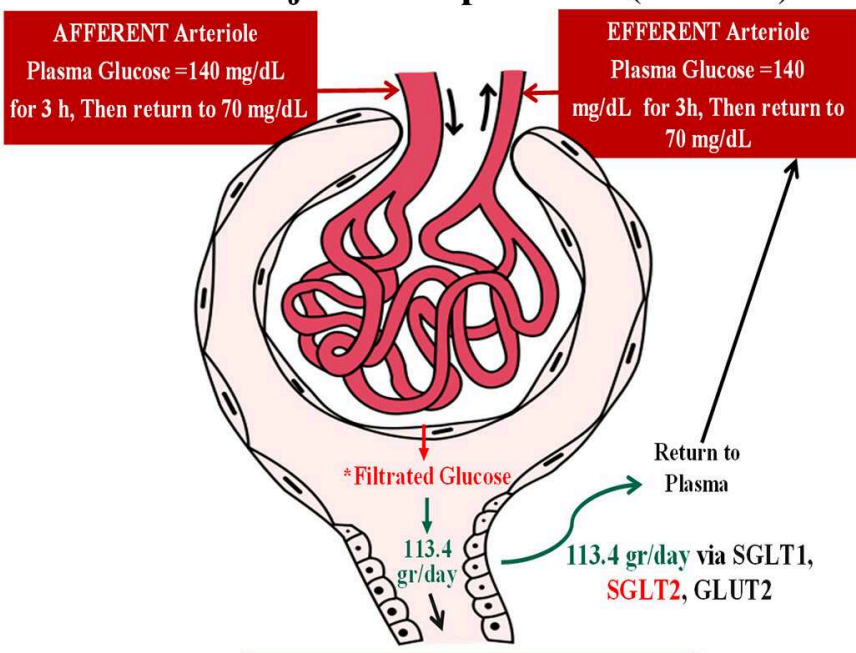

Urinary glucose excretion $=0$ gr/day
C

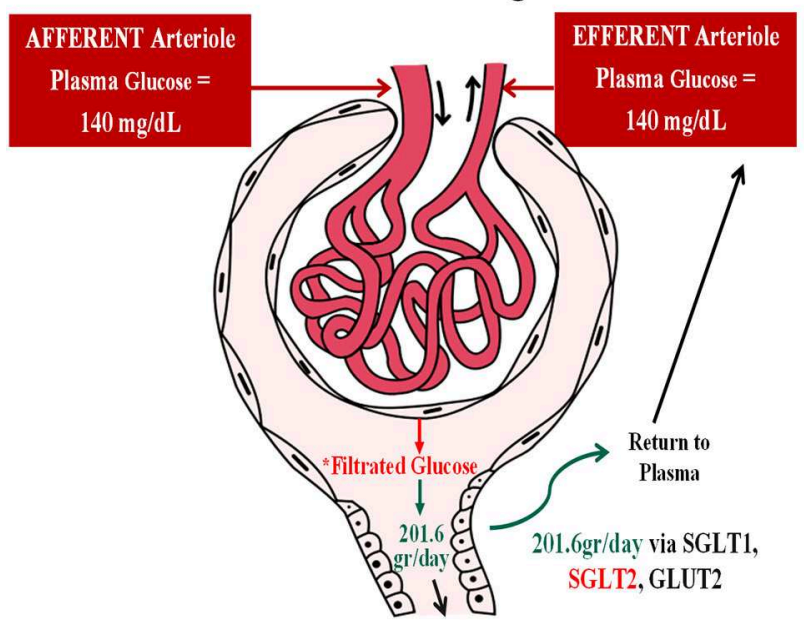

Urinary glucose excretion $=0$ gr/day
D T2DM: Postprandial (3meals)

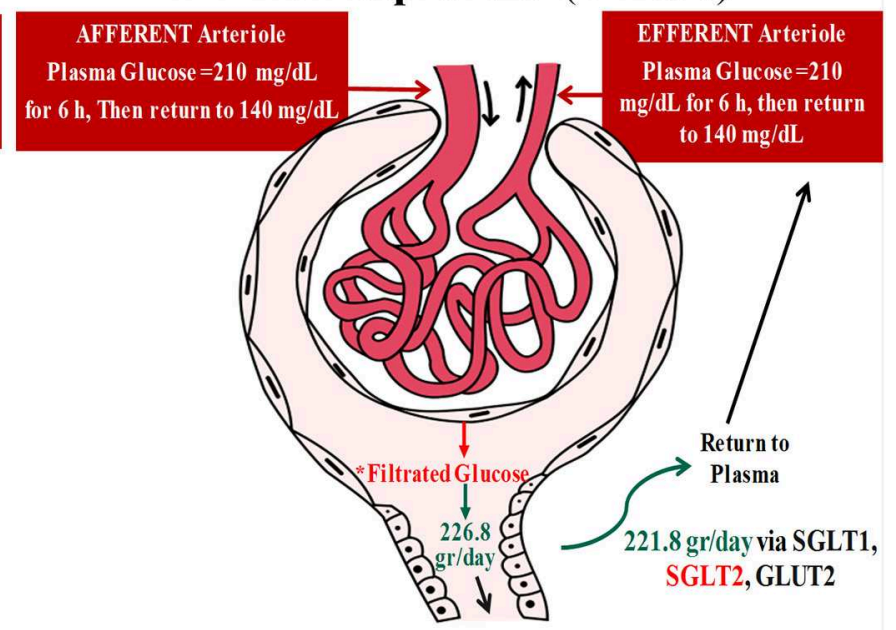

Urinary glucose excretion $=\mathbf{5} \mathrm{gr} / \mathrm{day}$

FIGURE 1 | Two hypothetical examples illustrating the postulated impact of meals on glucose and concomitant sodium uptake in the proximal tubule. (A) A non-diabetic subject with stable glucose levels of $70 \mathrm{mg} / \mathrm{dl}$ and a glomerular filtration rate (GFR) of $100 \mathrm{ml} / \mathrm{min}$. This individual will have a glucose reuptake of $70 \mathrm{mg} / \mathrm{min}(\sim 100 \mathrm{~g} /$ day $)$, as demonstrated below: Filtrated Glucose $=$ PGluc $\times$ GFR $=(70 \mathrm{mg} / \mathrm{dl} \times 100 \mathrm{ml} / \mathrm{min}) \times 24 \mathrm{~h}=(0.7 \mathrm{mg} / \mathrm{ml} \times 100 \mathrm{ml} / \mathrm{min}) \times 24 \mathrm{~h}=(70$ $\mathrm{mg} / \mathrm{min}) \times 24 \mathrm{~h}=70 \div 1,000 \mathrm{~g} / \mathrm{min} \times 1,440 \mathrm{~min}=100.8 \mathrm{~g} /$ day. (B) This individual, now having three meals per day with three post-prandial increments of glucose levels to $140 \mathrm{mg}$ for an hour will have an extra $12.6 \mathrm{~g}$ of glucose reabsorption per day: Filtrated Glucose $=\mathrm{PGluc} \times \mathrm{eGFR}=(70 \mathrm{mg} / \mathrm{dl} \times 100 \mathrm{ml} / \mathrm{min}) \times 21 \mathrm{~h}+(140$ $\mathrm{mg} / \mathrm{dl} \times 100 \mathrm{ml} / \mathrm{min}) \times 3 \mathrm{~h}=(0.7 \mathrm{mg} / \mathrm{ml} \times 100 \mathrm{ml} / \mathrm{min}) \times 21 \mathrm{~h}+(1.4 \mathrm{mg} / \mathrm{ml} \times 100 \mathrm{ml} / \mathrm{min}) \times 3 \mathrm{~h}=(70 \div 1,000 \mathrm{~g} / \mathrm{min} \times 1,260 \mathrm{~min})+(140 \div 1,000 \mathrm{~g} / \mathrm{min} \times 180$ $\mathrm{min})=88.2+25.2=113.4 \mathrm{~g} /$ day. Thus, $\Delta$ Glucose reabsorbed following meals $=113.4-100.8=12.6 \mathrm{~g}$. (C) A type 2 diabetes mellitus (T2DM) patient with fasting glucose levels of $140 \mathrm{mg} / \mathrm{dl}$ without glycosuria and with a GFR of $100 \mathrm{ml} / \mathrm{min}$ will reabsorb $140 \mathrm{mg}$ glucose/min, about $200 \mathrm{~g} / 24 \mathrm{~h}$ while fasting: Filtrated Glucose $=$ PGluc $\times$ eGFR $=(140 \mathrm{mg} / \mathrm{dl} \times 100 \mathrm{ml} / \mathrm{min}) \times 24 \mathrm{~h}=(1.4 \mathrm{mg} / \mathrm{ml} \times 100 \mathrm{ml} / \mathrm{min}) \times 24 \mathrm{~h}=(140 \mathrm{mg} / \mathrm{min}) \times 24 \mathrm{~h}=140 \div 1,000 \mathrm{~g} / \mathrm{min} \times 1,440 \mathrm{~min}=201.6 \mathrm{~g} / \mathrm{day}$. (D) Filtrated glucose in this patient post-prandial (three meals) $=$ PGluc $\times$ eGFR $=(140 \mathrm{mg} / \mathrm{dl} \times 100 \mathrm{ml} / \mathrm{min}) \times 18 \mathrm{~h}+(210 \mathrm{mg} / \mathrm{dl} \times 100 \mathrm{ml} / \mathrm{min}) \times 6 \mathrm{~h}=(1.4 \mathrm{mg} / \mathrm{ml}$ $\times 100 \mathrm{ml} / \mathrm{min}) \times 18 \mathrm{~h}+(2.1 \mathrm{mg} / \mathrm{ml} \times 100 \mathrm{ml} / \mathrm{min}) \times 6 \mathrm{~h}=(140 \div 1,000 \mathrm{~g} / \mathrm{min} \times 1,080 \mathrm{~min})+(210 \div 1,000 \mathrm{~g} / \mathrm{min} \times 360 \mathrm{~min})=151.2+75.6=226.8 \mathrm{~g} / \mathrm{day}$. Taking into account that this subject loses $\sim 5 \mathrm{~g}$ of glucose per day, $\Delta$ Glucose reabsorbed $=226.8-201.6=25.2 \mathrm{~g}-5 \mathrm{~g} / \mathrm{day}=20.2 \mathrm{~g} / \mathrm{day}$.

As proximal tubular transport of $\mathrm{Na}^{+}$and glucose is matched with a 1:1 molar ratio for sodium-glucose co-transporter 2 (SGLT2), the non-diabetic individual (example 1), moving from a 24-h fast to regular eating, will have an additional daily uptake of $70 \mathrm{mEq} \mathrm{Na}{ }^{+}$, while the diabetic patient (example 2) will have an enhanced sodium reuptake of $111 \mathrm{mEq}$. These amounts correspond to additional retentions of 4 and $6.5 \mathrm{~g}$ of sodium chloride per day for the non-diabetic and diabetic individuals, respectively. It translates to added water retentions of 0.5 and $0.66 \mathrm{~L}$, respectively, in order to maintain extracellular osmolality, roughly the anecdotal reported acute weight reduction following fasting for a day, immediately reversed upon eating. 
Maoz et al. (12) reported that the atrial natriuretic peptide (ANP) levels doubled within 4 days in fasting obese hypertensive patients in parallel with urine sodium loss, suggesting a role for ANP in fasting natriuresis. Yet, a restricted diet in these patients was composed of $50 \%$ carbohydrates. Furthermore, in another study, obese patients with fasting natriuresis over 7 days showed no initial change in the atrial natriuretic factor, which even declined later on (13). In these experiments, a gradual increase in plasma aldosterone developed over time, without changes in renin and cortisol, altogether excluding a role for RAAS and natriuretic peptides in fasting natriuresis. In additional studies, a role for aldosterone in glucose-mediated sodium retention has also been ruled out (14). Interestingly, the elevation of aldosterone in the early phase of fasting, which seems adaptative to the fasting-associated enhanced natriuresis and volume contraction, is poorly antagonized by an anti-aldosterone medication such as spironolactone, suggesting that the distal tubular site of the reabsorption of sodium is not the main site involved in fasting natriuresis, neither in the anti-natriuretic effect of post-fasting refeeding, rather suggesting the involvement of the proximal tubular site (15).

Alterations in sympathetic activity have also been evaluated. Fasting for a few days with profound natriuresis occurred in obese normotensive patients, with no increase of sympathetic activity (16). Furthermore, the sympathetic system was not shown to play a role in sodium excretion in fed conscious rats. In contrast, fasting natriuresis, but not diuresis, has been facilitated by unilateral sympathectomy, as compared with the contralateral innervated kidney, while the GFR remained unchanged (17), suggesting a role for renal sympathetic innervation in the preservation of sodium during diet restriction.

Insulin receptors are found in the glomeruli and in most nephron segments, suggesting a physiologic role in sodium and water homeostasis in response to abrupt post-prandial water and osmotic loads. Insulin-clamp studies, maintaining a stable filtered load of glucose, suggest an independent effect of insulin, likely enhancing post-prandial sodium retention at the diluting segment of the distal nephron (18). Indeed, recent reports have shown that insulin exerts a RAAS-independent post-prandial reclamation of water and sodium, likely mediated by a significant increase in the open probability of $\mathrm{ENaC}$ along collecting tubules (19). Additionally, insulin also directly stimulates SGLT2 expression, as illustrated in studies using renal tubule-specific insulin receptor knockout (KO) mice (20). Yet, this likely does not explain the abrupt reversal of natriuresis following a short fasting period.

In contrast, glucagon was thought to participate in fasting natriuresis and refeeding antinatriuresis via antimineralocorticoid effects (11), but as exposed earlier, the involvement of aldosterone at the distal tubule does not seem to play a major role. A direct tubular effect of increased glucagon during fasting as the causative effect of fasting natriuresis and a reduced glucagon during carbohydrate refeeding as the cause of refeeding antinatriuresis has been ruled out, despite an indirect minor effect through ketogenesis being still possible (21). Indeed, an increased anionic ketone production mediated by reduced insulin and elevated glucagon levels during fasting is initially associated with an enhanced urinary sodium excretion to catch the urine excretion of the anionic ketone overproduction (3). Later on, the increased production of ammonium replaces the urinary sodium excretion, maintaining obligatory cation coverage of the metabolically generated anions as a major mechanism responsible for fasting natriuresis (22). Corroborating our initial hypothesis, and in view of the glucagon-ketogenesis pathway, the use of SGLT2-I was consistently associated with an increased risk of euglycemic ketoacidosis in treated diabetic patients (23), and it was recently shown that SGLT2-I in mice act on ketogenesis directly rather than via glucagon (24).

Otherwise, a plausible gut effect mediated by the kallikreinkinin system following intragastric glucose administration has been shown to induce renal antidiuresis in anesthetized fasting rats. Yet, in these studies, natriuresis has been triggered by the administration of ANP (25).

Fasting natriuresis occurs despite enhanced $\mathrm{Na} / \mathrm{K} / \mathrm{ATPase}$ expression and activity within $24 \mathrm{~h}$, both in the cortex and the medulla, as shown in psammomas (26). This shows that basolateral $\mathrm{Na} / \mathrm{K} / \mathrm{ATPase}$ is not involved in fasting natriuresis, which may, in part, reflect an adaptation to an enhanced sodium delivery to the distal nephron segments in response to a reduced proximal tubular sodium reabsorption.

Noteworthy is that, in addition to glucose, fructose, and sucrose also exert sodium retention in fasting natriuretic normotensive persons (27). Sucrose may do so following its hydrolysis with the release of glucose. Fructose is also reabsorbed in proximal tubules, coupled with sodium uptake at a $1: 1$ ratio. This transport is likely triggered by $\mathrm{NH}_{3}$-mediated (28) activation of SGLT4/5 and GLUT2 in the luminal and basolateral membranes, respectively (29).

Our theory ignores adaptive responses to a reduced proximal tubular sodium transport, affecting GFR and sodium and water handling along the nephron. Yet, such responses, triggered by the activation of the RAAS axis, are turned on following protracted fasting, when effective volume depletion becomes apparent, as experimentally shown in fasting rabbits (30). Furthermore, physiologic responses to SGLT2 inhibitors illustrate that distal tubular sodium reuptake does not fully compensate for sodium loss by the inhibition of proximal tubular glucose-sodium co-transport.

Our review ignores the possible additional effect of the different nutrition of lean and obese patients that could affect renal sodium and water handling through multiple mechanisms, such as the enhancement of GFR by amino acids, or dietrelated modifications of renal transport mechanisms, for instance alterations in islet cell excretion of insulin and glucagon and the release of various gut peptides and adiponectin from adipose tissues. The latter, for instance, suppresses SGLT2 in proximal tubules. Thus, a decreased adiponectin in obese patients leads to an enhanced SGLT2 expression, likely governing salt retention and hypertension (31). Another example is the parallel upregulation of ion transporters and SGLT2 by a fructoseenriched diet (32).

As already mentioned above, our hypothesis takes into account the profound upregulation of SGLT2 in type 2 


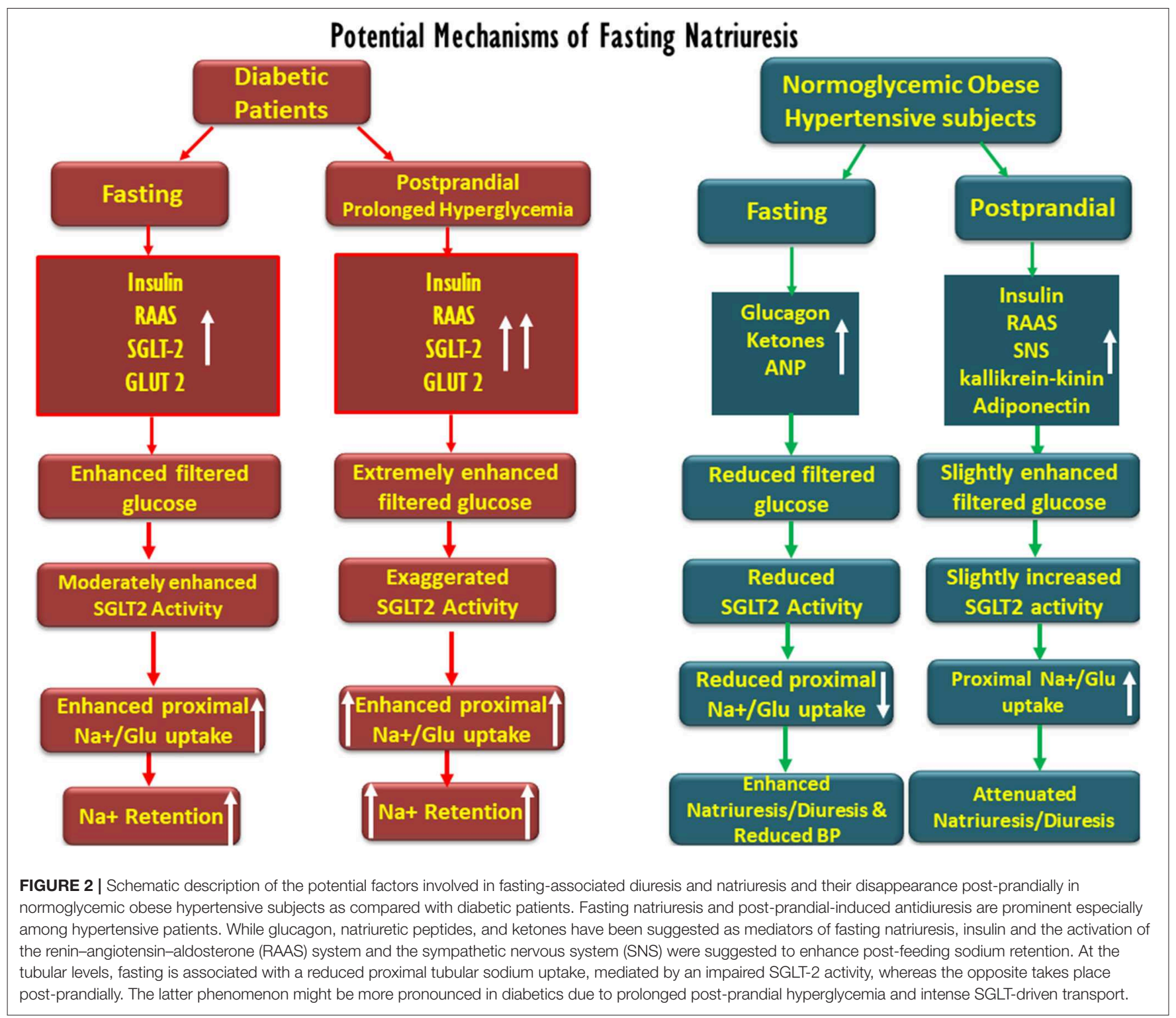

diabetics, likely enhancing post-prandial water and sodium retention. Additionally, other factors, not fully addressed here, are ensuing volume depletion due to osmotic diuresis, characteristic of uncontrolled diabetes and the non-ketotic hyperosmolar state, with the activation of the RAAS axis and renal sympathetic activity, reduction in GFR, and the likely inhibition of natriuretic peptides and the induction of diverse tubular sodium transporters (33-35). Such physiologic alterations may play in concert with post-prandial antidiuresis and salt retention, related to glucose-sodium co-transport, and counteract fasting-associated diuresis and natriuresis.

Abundant expression of natriuretic peptide clearance receptors (NPr-C) in the adipose tissues of obese patients attenuates diuresis in response to natriuretic peptides by reducing their accessibility to active receptors (36). Possibly, fasting could lead to a reduced NPr-C expression, facilitating natriuresis. Yet, most of the above-mentioned processes are likely retarded and do not explain early and abrupt diuresis upon fasting, immediately reversed by refeeding.

Conclusively, although the applicability to human physiology of some of the findings shown in animals and reported above may be questionable, various mechanisms likely participate in extracellular sodium and volume homeostasis during intermittent feeding and fasting, as summarized in Figure 2. Yet, with no clear-cut evidence for the physiologic mechanisms fully explaining this phenomenon, early fasting diuresis and natriuresis, and post-prandial sodium and water retention may involve the attenuation and intensification of proximal tubular sodium transport, respectively, determined by tubular intraluminal glucose content. Our hypothesis may also provide a physiologic basis for fasting-related reduced blood pressure in 
hypertension. Fasting natriuresis may have a clinical relevance beyond being an interesting anecdote, and clinical studies are designed, assessing intermittent fasting as a potential therapeutic intervention in the management of the components of metabolic syndrome (10). Our proposed theory, therefore, deserves challenging by experimental and clinical studies. A reasonable approach might be the assessment of renal sodium and water handling when moving from fasting to feeding at baseline and in the presence of SGLT blockade. If proven correct, our hypothesis may form the theoretical basis for a broader clinical use of SGLT2 inhibitors, besides the management of T2DM.

\section{REFERENCES}

1. Veverbrants E, Arky RA. Effects of fasting refeeding. I. Studies on sodium, potassium and water excretion on a constant electrolyte and fluid intake. $J$ Clin Endocrinol Metabol. (1969) 29:55-62. doi: 10.1210/jcem-29-1-55

2. Schloeder FX, Stinebaugh BJ. Renal tubular sites of natriuresis of fasting and glucose-induced sodium conservation. Metabolism. (1970) 19:1119-28. doi: 10.1016/0026-0495(70)90037-5

3. Kerndt PR, Naughton JL, Driscoll CE, Loxterkamp DA. Fasting: the history, pathophysiology and complications. West J Med. (1982) 137:379-99.

4. Kraikitpanitch S, Chrysant SG, Lindeman RD. Natriuresis and carbohydrateinduced antinatriuresis in fasted, hydrated hypertensives. Proc Soc Exp Biol Med. (1975) 149:319-24. doi: 10.3181/00379727-149-38798

5. Fitzgerald SM, Hall JE, Brands MW. Rapid hypotensive response to fasting in spontaneously hypertensive rats. Am J Hypertens. (2001) 14:1123-7. doi: 10.1016/s0895-7061(01)02209-9

6. Patel DK, Strong J. The pleiotropic effects of sodium-glucose cotransporter2 inhibitors: beyond the glycemic benefit. Diabetes Ther. (2019) 10:1771-92. doi: 10.1007/s13300-019-00686-z

7. O'neill J, Fasching A, Pihl L, Patinha D, Franzen S, Palm F. Acute SGLT inhibition normalizes $\mathrm{O}_{2}$ tension in the renal cortex but causes hypoxia in the renal medulla in anaesthetized control and diabetic rats. Am J Physiol. (2015) 309:F227-34. doi: 10.1152/ajprenal.00689.2014

8. Ghezzi C, Loo DDF, Wright EM. Physiology of renal glucose handling via SGLT1, SGLT2 and GLUT2. Diabetologia. (2018) 61:2087-97. doi: 10.1007/s00125-018-4656-5

9. Mager DE, Wan R, Brown M, Cheng A, Wareski P, Abernethy DR, et al. Caloric restriction and intermittent fasting alter spectral measures of heart rate and blood pressure variability in rats. FASEB J. (2006) 20:631-7. doi: 10.1096/fj.05-5263com

10. Tripolt NJ, Stekovic S, Aberer F, Url J, Pferschy PN, Schroder S, et al. Intermittent fasting (alternate day fasting) in healthy, non-obese adults: protocol for a cohort trial with an embedded randomized controlled pilot trial. Adv Ther. (2018) 35:1265-83. doi: 10.1007/s12325-0180746-5

11. Spark RF, Arky RA, Boulter PR, Saudek CD, O'brian JT. Renin, aldosterone and glucagon in the natriuresis of fasting. N Engl J Med. (1975) 292:1335-40. doi: 10.1056/NEJM197506192922506

12. Maoz E, Shamiss A, Peleg E, Salzberg M, Rosenthal T. The role of atrial natriuretic peptide in natriuresis of fasting. J Hypertens. (1992) 10:1041-4.

13. Donckier JE, Kolanowski J, Berbinschi A, Gerard G, Ketelslegers JM. Relationship between natriuresis and changes in plasma atrial natriuretic factor, renin activity and aldosterone levels in fasting obese subjects. Diabete Metabol. (1990) 16:278-283.

14. Kolanowski J, Desmecht P, Crabbe J. Sodium balance and renal tubular sensitivity to aldosterone during total fast and carbohydrate refeeding in the obese. Euro J Clin Invest. (1976) 6:75-83. doi: 10.1111/j.1365-2362.1976.tb00496.x

15. Boulter PR, Spark RF, Arky RA. Effect of aldosterone blockade during fasting and refeeding. Am J Clin Nutr. (1973) 26:397-402. doi: 10.1093/ajcn/26.4.397

\section{DATA AVAILABILITY STATEMENT}

The datasets generated for this study are available on request to the corresponding author.

\section{AUTHOR CONTRIBUTIONS}

$\mathrm{SH}, \mathrm{MB}$, and ZA proposed the new concept, participated in preparing the manuscript, and the figures. AS and $\mathrm{MM}$ participated in retrieving and elaborating on the relevant literature. SH, MB, AS, MM, and ZA wrote, read, and approved the final manuscript.

16. Koppeschaar HP, Meinders AE, Schwarz F. The effect of modified fasting on blood pressure and sympathetic activity: a correlation? Int $J$ Obes. (1983) 7:569-74.

17. Szenasi G, Bencsath P, Szalay L, Takacs L. Fasting induces denervation natriuresis in the conscious rat. Am J Physiol. (1985) 249:F753-8. doi: 10.1152/ajprenal.1985.249.5.F753

18. Defronzo RA, Cooke CR, Andres R, Faloona GR, Davis PJ. The effect of insulin on renal handling of sodium, potassium, calcium, and phosphate in man. J Clin Invest. (1975) 55:845-55. doi: 10.1172/JCI1 07996

19. Klemens CA, Brands MW, Staruschenko A. Postprandial effects on electrolyte homeostasis in the kidney. Am J Physiol. (2019) 317:F1405-8. doi: 10.1152/ajprenal.00350.2019

20. Nizar JM, Shepard BD, Vo VT, Bhalla V. Renal tubule insulin receptor modestly promotes elevated blood pressure and markedly stimulates glucose reabsorption. JCI Insight. (2018) 3:95107. doi: 10.1172/jci.insight. 95107

21. Kolanowski J, Salvador G, Desmecht P, Henquin JC, Crabbe J. Influence of glucagon on natriuresis and glucose-induced sodium retention in the fasting obese subject. Euro J Clin Invest. (1977) 7:167-75. doi: 10.1111/j.1365-2362.1977.tb01593.x

22. Sigler MH. The mechanism of the natriuresis of fasting. J Clin Invest. (1975) 55:377-87. doi: 10.1172/JCI107941

23. Taylor SI, Blau JE, Rother KI. SGLT2 inhibitors may predispose to ketoacidosis. J Clin Endocrinol Metab. (2015) 100:2849-52. doi: $10.1210 /$ jc. $2015-1884$

24. Capozzi ME, Coch RW, Koech J, Astapova I, Wait JB, Encisco SE, Douros JD, et al. The limited role of glucagon for ketogenesis during fasting or in response to SGLT2 inhibition. Diabetes. (2020) db191216. doi: 10.2337/db19-1216

25. Croxatto HR, Figueroa XF, Roblero J, Boric MP. Kinin B2 receptors mediate blockade of atrial natriuretic peptide natriuresis induced by glucose or feeding in fasted rats. Hypertension. (1999) 34:826-31. doi: 10.1161/01.hyp.3 4.4.826

26. Scherzer P, Nachliel I, Ziv E, Bar-On H, Popovtzer MM. Effects of variations in food intake on renal sodium pump activity and its gene expression in Psammomys kidney. Am J Physiol. (2000) 279:F1124-31. doi: 10.1152/ajprenal.2000.279.6.F1124

27. Rebello T, Hodges RE, Smith JL. Short-term effects of various sugars on antinatriuresis and blood pressure changes in normotensive young men. Am J Clin Nutr. (1983) 38:84-94. doi: 10.1093/ajcn/38.1.84

28. Queiroz-Leite GD, Crajoinas RO, Neri EA, Bezerra CN, Girardi AC, Reboucas NA, et al. Fructose acutely stimulates NHE3 activity in kidney proximal tubule. Kidney Blood Pressure Res. (2012) 36:320-34. doi: 10.1159/000343390

29. Gonzalez-Vicente A, Cabral PD, Hong NJ, Asirwatham J, Saez F, Garvin JL. Fructose reabsorption by rat proximal tubules: role of $\mathrm{Na}(+)$-linked cotransporters and the effect of dietary fructose. Am J Physiol. (2019) 316:F473-80. doi: 10.1152/ajprenal.00247.2018

30. Nocenti MR, Simchon S, Cizek LJ. Analysis of the renin-angiotensin system during fasting in adult male rabbits. Proc Soc Exp Biol Med. (1975) 150:142-7. doi: 10.3181/00379727-150-38991 
31. Tanaka M, Itoh H. Hypertension as a metabolic disorder and the novel role of the gut. Curr Hypertens Rep. (2019) 21:63. doi: 10.1007/s11906-019-0964-5

32. Ng HY, Lee YT, Kuo WH, Huang PC, Lee WC, Lee CT. Alterations of renal epithelial glucose and uric acid transporters in fructose induced metabolic syndrome. Kidney Blood Pressure Res. (2018) 43:1822-31. doi: 10.1159/000495814

33. Shin SJ, Lee YJ, Hsiao PJ, Tsai JH. Increased urinary atrial natriuretic peptide-like immunoreactivity excretion but decreased plasma atrial natriuretic peptide concentration in patients with hyperosmolarhyperglycemic nonketotic syndrome. Diabetes Care. (1999) 22:1181-5. doi: $10.2337 /$ diacare.22.7.1181

34. Ansary TM, Nakano D, Nishiyama A. Diuretic effects of sodium glucose cotransporter 2 inhibitors and their influence on the reninangiotensin system. Int J Mol Sci. (2019) 20:629. doi: 10.3390/ijms200 30629

35. Silva Dos Santos D, Polidoro JZ, Borges-Junior FA, Girardi ACC. Cardioprotection conferred by sodium-glucose cotransporter 2 inhibitors: a renal proximal tubule perspective. Am J Physiol. (2020) 318:C328-36. doi: 10.1152/ajpcell.00275.2019

36. Dessi-Fulgheri P, Sarzani R, Rappelli A. The natriuretic peptide system in obesity-related hypertension: new pathophysiological aspects. J Nephrol. (1998) 11:296-9.

Conflict of Interest: The authors declare that the research was conducted in the absence of any commercial or financial relationships that could be construed as a potential conflict of interest.

Copyright (C) 2020 Heyman, Bursztyn, Szalat, Muszkat and Abassi. This is an openaccess article distributed under the terms of the Creative Commons Attribution License (CC BY). The use, distribution or reproduction in other forums is permitted, provided the original author(s) and the copyright owner(s) are credited and that the original publication in this journal is cited, in accordance with accepted academic practice. No use, distribution or reproduction is permitted which does not comply with these terms. 